commission foresees a network of equipotent laboratories, one working for the prosecution and one for the defence. That could work, but probably not well. Especially in technically novel fields, some laboratories will be more equal than others. And it is unlikely that even the bestprovided forensic service would be so well-supplied with expertise that it could advise both sides in a case impartially, and without conflict of interest. And while the reasoning is clear behind the proposal that prosecution and defence should agree before a trial what the forensic evidence is and what interpretations they will each put upon it, impartiality is not self-evident.

That is why it would be far preferable that the forensic services should be neither private nor a creature of the government, but servants of the courts. If it were decreed that, in a criminal trial, forensic evidence would ordinarily be provided by a laboratory functioning under the direct supervision of the judicial system, doubts about the authenticity of evidence could hardly arise. The obvious difficulty is that opportunities would persist for analysis and interpretation of data to rest with individuals (one of the origins of many recent miscarriages of justice), but, as the newest graduate student knows, the best way to make sense of data is to discuss them in an open forum. That argues for a forensic service run on collegiate, not hierarchical, lines. If that should be judged unworkable, the only feasible alternative is to abandon the adversarial system, to precede each accusation by a judicial assessment of the evidence (as by an investigatory magistrate) and to allow judges to employ experts to advise them on the details of technical cases (which already happens in British commercial courts).

Although lawyers may dismiss the notion that the need to deal with forensic and other technical evidence may in itself force a reconstruction of the basis of the British judicial system, that would be mistaken and complacent. Faulty forensic evidence has already been responsible for more than its fair share of faulty convictions, and under the present British system can only become a greater nuisance. So too will multiply the occasions when disputes that can be settled only by an assessment of the probabilities of contradictory events are, instead, decided by the intellectual equivalent of the tossing of a coin, and by people who are not educated to understand the processes involved.

Remedies of that kind will not avoid abuses of administrative law, such as the banishment of students to Northern Ireland for no better reason than that a government minister has been persuaded by untested and unpublished evidence - and that they have Irish accents. And the Prevention of Terrorism Act is justifiable by the continuing (even worsening) violence in Northern Ireland. But those now faced with the need for the dramatic improvement of British justice may reasonably calculate that the present violence owes at least some of its bitterness to the way in which wrongly chosen Irish men and women have been the most prominent victims of injustice in the past few years.

\section{Social science's summit}

The Tokyo summit may have put social science on the map, but its problems and their remedies still lie ahead.

IT must mean something good for social scientists that last week's summit meeting of the heads of government of the seven richest countries, called G7, should have spent most of its time on issues with their roots in these recently neglected fields of study. Certainly it is a long time since such a meeting has drawn attention to the increasing age of its participants' populations, and to have given its opinion that steps would have to be taken to remove part of the cost thereof from public budgets. Demography and welfare studies refer. And, for good reason, world leaders are worried about unemployment. Will they now listen more readily to the solutions canvassed for many years by the softer sciences?

The capacity of those concerned to deal effectively with these issues nevertheless depends on the meeting preceding the summit at which Canada, the European Communities, Japan and the United States hammered out the bare bones of an agreement to reduce the tariffs they now levy on imports. If the agreement sticks (it requires ratification in each case) those concerned can expect to become richer, they can expect that the latest version of the GATT, or the General Agreement on Tariffs and Trade (already two and a half years late), may be signed before the year is up and they can expect that the problems that perplexed them last week will be less intractable.

In rich countries such as those of G7, employment should be no problem. Everybody knows the solution. The first need is, by education, to increase the degree and the amount of skill deployed so that technically advanced occupations substitute for those adding very little to the value of the raw materials they consume; then there is enough cash in circulation to employ more of each population in the service occupations (education included). Among G7 countries, France has most consistently followed this path in the past decade; it is to be hoped that its new government does not lose patience while waiting for the rewards to drop into its lap.

The ageing issue is linked with that of employment. For one thing, why set the elderly to growing roses when, healthier than they used to be, they could continue to earn a living for themselves? The now common riposte - that younger people need the jobs more urgently, and that the elderly stultify the organizations to which they belong - has some force, but the less in prosperous societies. But what should be clear everywhere is that the cost of pensions for the elderly should not be counted as a return of savings made over a life at work, but as the cost of welfare for those in need.

Apparent problems are thus potentially illusions. How to make them vanish? Clinching a new GATT is the simplest way. Then there would be funds with which to embark on the soluble problems. But they will not be spent in that way unless heads of government are more resolute than they seemed last week. In this new competition for prosperity, the winners will be found to have looked ahead. 